\title{
MEASUREMENT AND ANALYSIS OF COASTAL WAVES ALONG THE NORTH SEA AREA OF CHINA
}

\author{
Shu-zheng SUN \\ Hui LI \\ Hui SUN \\ College of Shipbuilding Engineering, Harbin Engineering University, China
}

\begin{abstract}
Taking advantage of coastal wave environment to carry out scaled ship model test is an effective testing technology for ship performance. In this paper, the method of spectral analysis is adopted to calculate the significant wave height, period, wave spectrum and some other parameters of some places along the North Sea area of China. The measured wave spectrum and the ocean spectrum are handled into non-dimensional form to evaluate their similarity. The influence of wind direction and tide on coastal waves was analyzed. And the results indicate that the coastal wave spectrum is similar to the ocean spectrum under some specific conditions.
\end{abstract}

Keywords: coastal wave, measurement, buoy, spectral analysis

\section{INTRODUCTION}

Sea wave research has significance on marine military activities, the design of marine structures, the construction of marine projects, marine development, shipping transportation, marine fishing, etc. One important method of sea wave research is to measure actual sea wave environments. Wave observation technologies have developed rapidly in recent years, with a great variety of wave observation devices having been invented according to different working principles, such as wave pole-type, pressure-type, acoustics-type, gravity-type, remote-sensing wave device, etc. Users can employ different devices according to different demands so as to be adapted to specific sea situations [1].

Compared with environments of distant oceans, inshore waters are relative shallow with relative small waves, which makes the waters good for carrying out scaled self-propelled testing of ship models. Meanwhile, with great influence caused by meteorology, tides, etc., sea wave environments in inshore waters have more uncertain factors. Therefore, measuring actual environment of inshore sea waves, adopting spectral analysis method to calculate sea wave spectrum and to make statistics on wave elements, discussing the similarity between sea wave spectrum in inshore covert waters and actual ocean spectrum, and making research on the environmental characteristics of wind and wave in inshore waters, will have significance on utilizing inshore waters to carry out scaled ship model testing as well as research on ship adaptability to environment which are under actual sea wave environment [2].

This article carries out measurement on a number of inshore sea wave environments of the Yellow Sea and the Bohai Sea by utilizing buoy-typed wave height gauge, makes analysis on the measured sea wave data by adopting spectral analysis method, acquires statistics of wave elements, explores the similarity of actual wave spectrum and ocean spectrum, and makes 
analysis on the influence of environmental conditions on sea wave elements, such as water depth, meteorology and tides.

\section{ACTUAL WAVE MEASUREMENT AND SPECTRUM ANALYSIS METHODS}

\section{THE DESIGN OF WAVE HEIGHT METER}

This article utilizes a self-made buoy-typed wave height meter to carry out wave measurement. The gauge is small, lightweight, low in cost, convenient for carrying, and easy for operating. The wave height meter adopts the principle of acceleration of gravity to conduct the ocean wave measurement. When the ocean wave performs a porpoising with the change of the wave surface, the vertical acceleration sensor installed in the buoy will output a time history signal which reflects the accelerated speed of the porpoising of the wave surface. After conducting a Fourier transform and a quadratic integral processing on the signal, we can get various kinds of statistical height values of the wave surface and its corresponding period of the wave $[3,4]$.

The buoy has a spherical overall shape, which synthetically considers its resistance to capsizing and its motion response. The wave height meter chooses a ball of $0.4 \mathrm{~m}$ diameter as the buoy body of it. The material of the body is fiberglass, while the material of the hatch cover and the hatch flange is stainless steel. Install the acceleration sensor at the center-of-gravity position of the body, install the ballast and fix it at the bottom, and keep the waterline at the maximum-section area, where the rubber damper should be installed. The design plan of the wave height meter is shown as Figure 1 and Figure 2. The parameters of the acceleration sensor are shown in Table 1.

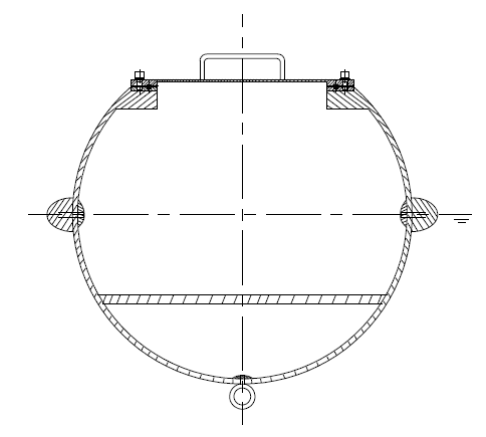

Fig.1 Plan of the wave height meter

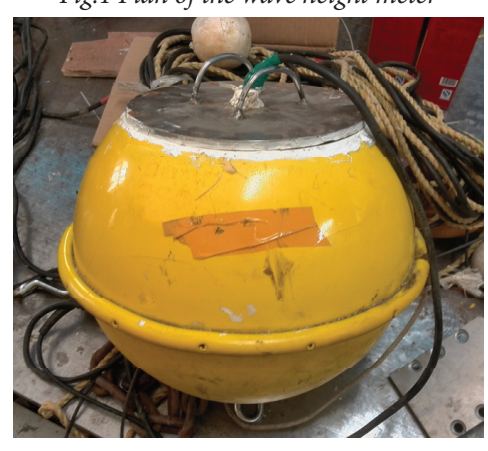

Fig. 2 Photo of the wave height meter
Table 1. Parameters of the acceleration sensor

\begin{tabular}{|c|c|c|c|}
\hline Type & $\begin{array}{c}\text { Acceleration } \\
\text { Range } \\
{[\mathrm{g}]}\end{array}$ & $\begin{array}{c}\text { Frequency } \\
\text { Response } \\
{[\mathrm{Hz}]}\end{array}$ & $\begin{array}{c}\text { Supply Voltage } \\
{[\mathrm{V}]}\end{array}$ \\
\hline $\begin{array}{c}\text { KISTLER } \\
8303 \mathrm{~A} 2\end{array}$ & $-2 \sim+2$ & $0-150$ & $9 \sim 20$ \\
\hline \multicolumn{3}{|c|}{ Conversion:1g $=9.80665 \mathrm{~m} / \mathrm{s}^{2}$} \\
\hline
\end{tabular}

\section{ESTIMATING THE OCEAN WAVE SPECTRUM WITH THE CORRELATION FUNCTION METHOD}

This paper uses the correlation function method to estimate the ocean wave spectrum. This method firstly calculates the correlation function and obtains the sampling interval $(\Delta t=0.5 \sim 2)$. The correlation function is

$$
\begin{aligned}
R(v \Delta t) & =\frac{1}{N-v} \sum_{n=1}^{N-v} x\left(t_{n}+v \Delta t\right) x\left(t_{n}\right) \\
\tau & =v \Delta t, v=0,1,2, \cdots, m
\end{aligned}
$$

And then it will estimate the rough value of spectrum, which is defined $\mathrm{Ln}$ as the rough value of spectrum corresponding to the frequency fn

$$
\begin{aligned}
L_{n}= & \frac{2 \Delta t}{\pi}\left[\frac{1}{2} R(0)+\sum_{v=1}^{m-1} R(v \Delta t) \cos \frac{\pi v n}{m}\right. \\
& \left.+\frac{1}{2} R(m \Delta t) \cos \pi n\right] n=0,1,2, \cdots, m
\end{aligned}
$$

Finally it will smooth the rough value of spectrum, making different $R(v \Delta t)$ have different weights. It usually adopts the Hamming smooth processing, and the spectrum value after smooth processing is

$$
S\left(\omega_{n}\right)=0.23 L_{n-1}+0.54 L_{n}+0.23 L_{n+1}
$$

When calculating the wave height based on the ocean wave spectrum, the rth order spectral moments should be calculated first

$$
m=\sigma=\int^{\infty} \omega S(\omega) d \omega
$$

The significant wave height and the average period are respectively

$$
H_{1 / 3}=4 \sqrt{m_{0}} \quad, T_{0}=2 \pi \sqrt{m_{0} / m_{2}}
$$




\section{Common Ocean Spectrum Formula}

(1) ITTC Spectrum

$$
S_{\zeta}(\omega)=\frac{A}{\omega^{5}} e^{-\frac{B}{\omega^{4}}}
$$

Here, when $A=8.10 \times 10^{-3} g^{2}, B=3.11 /\left(h_{1 / 3}\right)^{2}$, it is the ITTC single parameter spectrum; and when $A=173 h_{1 / 3}{ }^{2} / T_{1}^{4}$, $B=691 / T_{1}^{4}, T_{1}=2 \pi m_{0} / m_{1}$, it is the ITTC dual parameter spectrum.

(2) China Sea Spectrum

$$
S_{\zeta}(\omega)=\frac{0.74}{\omega^{5}} \exp \left[-\frac{g^{2}}{U^{2} \omega^{2}}\right]
$$

Here, $\omega$-wave frequency; $U$ - velocity of wind, $g=9.81 \mathrm{~m} / \mathrm{s}^{2}$. If the significant wave height $h_{1 / 3}$ is known, the velocity of wind $\mathrm{U}$ can be calculated by:

$$
U=6.28 \sqrt{h_{1 / 3}}
$$

\section{(3) Ochi-Hubble Six-parameter Spectrum}

Some of the actual wave spectra often show the bimodal shape, and sometimes a third peak will appear, which is much smaller than the other two peaks. Ochi and Hubble proposed a six-parameter spectrum formula, which divided the spectrum into two parts: low frequency and high frequency, with each part using three parameters-signified in the forms of significant wave height $H_{s}$, spectral peak frequency $\omega_{m}$ and shape parameter $\lambda$, namely,

$$
\begin{aligned}
& S_{\zeta}(\omega)=\frac{1}{4} \sum_{j} \frac{\left[\left(4 \lambda_{j}+1\right) \omega_{m j}{ }^{4} / 4\right]^{\lambda_{j}}}{\Gamma\left(\lambda_{j}\right)} \\
& \frac{H_{s j}^{2}}{\omega^{4 \lambda_{j}+1}} \exp \left[-\left(\frac{4 \lambda_{j}+1}{4}\right)\left(\frac{\omega_{m j}}{\omega}\right)^{4}\right]
\end{aligned}
$$

Where, $j=1,2$ respectively represent the low frequency and high frequency in the formula. In the formula, there are totally six parameters $H_{s 1}, H_{s 2}, \omega_{m 1}, \omega_{m 2}, \lambda_{1}, \lambda_{2}$, which according to the measured spectral forms can make the difference value between the theoretical spectrum and the experimental spectrum smallest, namely, with each change of the parameter [5-8].

\section{THE SIMILARITY ANALYSIS OF MEASURED SPECTRUM AND OCEAN SPECTRUM}

When discussing the problems that whether the wave spectrum in the covered coastal water and the actual ocean are similar or not, they are often transformed into the problems that whether the spectral shapes and the main characteristics of the two are similar or not. We make a nondimensional comparison between the wave spectrum in the measurement sea area and the ocean spectrum, the nondimensional number of spectrum adopts the wave elements as the parameters, usually expressing with $S(\omega) \cdot \bar{\omega} / m$ or $S(\omega) \cdot \omega_{m} / m_{0}$, among which $\varpi$ is the average circular frequency of spectrum, $\varpi=\sqrt{\int_{0}^{\infty} \omega^{2} S(\omega) d \omega / m_{0}}, \omega_{m}$ is the peak frequency and $m_{0}$ is the spectral area [9].

The manuscript should be written in English in a clear, direct and active style. All pages must be numbered sequentially, facilitating in the reviewing and editing of the manuscript.

\section{ANALYSIS OF TEST DATA}

Before actual ocean wave measurement, the wave height meter needs to be calibrated. The calibration is carried out in the ship model towing tank in Harbin Engineering University. The irregular wave theoretical spectrum generated by the wave maker is well consistent with the wave spectrum measured by the wave height meter.

The experiment group measures the coastwise wave at Rongcheng Jinghaiwei, Dalian Xiaoheishi, Dalian Xiaoping Island, Huludao Harbor and other places in the Yellow Sea and the Bohai Sea. The wave data are measured by the abovementioned buoy wave height meter and are collected every 0.05 second. Each collection lasts for more than 10 minutes and the sampling frequency is $20 \mathrm{~Hz}$. Information like the tide, the weather condition, the distance from the measuring spot to the coast and the water depth are recorded synchronously. The map of the sea area being measured is shown in Figure 3. Like the acceleration time duration of wave surface heaving was shown in Figure 4, and Figure5 shown is the process of releasing the buoy from the boat.

This paper presents the measurements and analyses results of sea waves at different tidal periods and with different wind directions at Huludao Harbor sea area, Xiaoheishi sea area in Bohai Sea and Xiaopingdao sea area, Jinghaiwei sea area in Yellow Sea. The measuring points are all over 1 nautical mile off the coasts and the water depth at the measuring waters is about 10 meters. The By measurements and analyses, it is found that there is relatively great influence of the tide and wind direction on the sea wave. During the flow phase period and the high-tide period, when the wind blows from the sea to the coast, the wave spectra of the measured waters are basically similar to the ocean wave spectra.

Figure 6 shows the wave spectra of Huludao sea area at the high water period. On the very day when the test is carried out at Huludao Harbor $\left(40^{\circ} 43^{\prime} \mathrm{N}, 121^{\circ} 00^{\prime} \mathrm{E}\right)$, the parameters of the tide, wind and water depth, and etc., are as follows:

On the very day, the time of tide: $01: 05$ with a height of $76 \mathrm{~cm}$; $9: 39,286 \mathrm{~cm} ; 16: 02,80 \mathrm{~cm}$. The tidal datum plane is $158 \mathrm{~cm}$ beneath the average sea level, in the time zone: GMT+8; There is a southerly wind above the sea, with a wind speed of about $5 \mathrm{~m} / \mathrm{s}$; and a water depth of about 8 meters in the test sea area. The significant wave heights $\left(\mathrm{H}_{1 / 3}\right)$ of the three groups of wave data recorded are respectively $0.14 \mathrm{~m}, 0.153 \mathrm{~m}$ and $0.161 \mathrm{~m}$. 


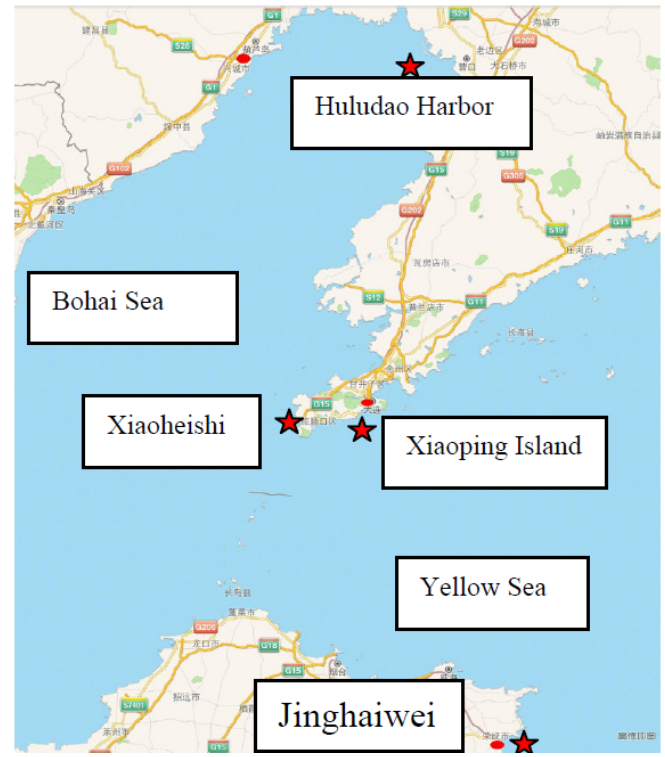

Fig.3 Map of the sea area being measured

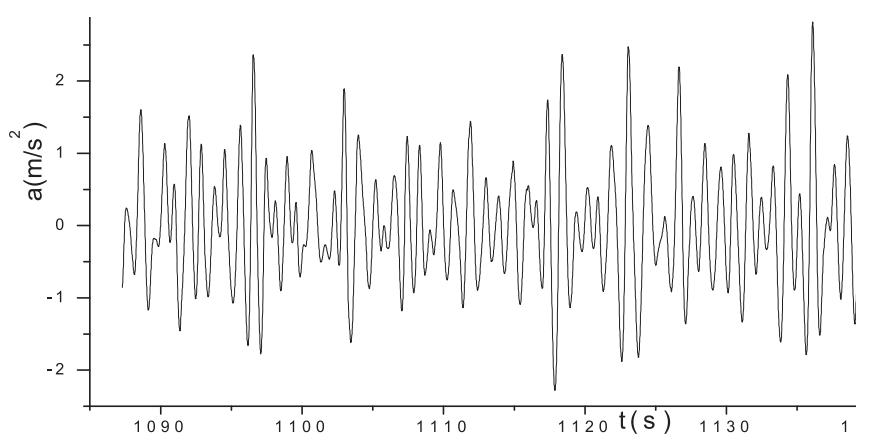

Fig. 4 The acceleration time duration of wave surface heaving

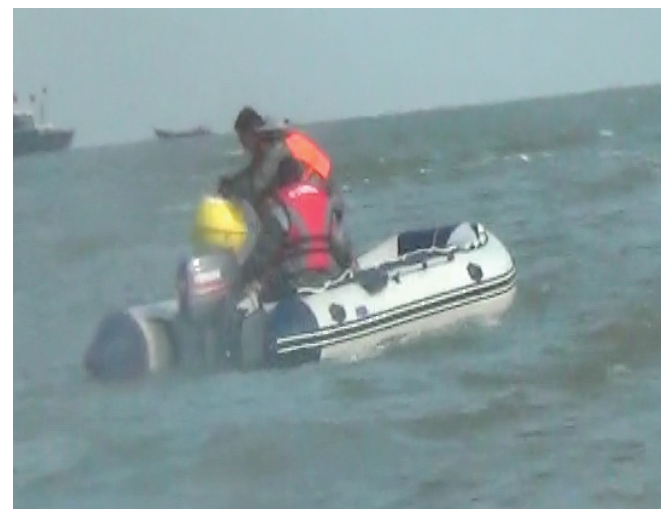

Fig.5 Releasing the buoy from the boat

Figure 7 indicates the wave spectra of the coastal flow phase at Xiaoping Island sea area in Dalian City. On the very day when the test is carried out at Xiaoping Island $\left(38^{\circ} 49^{\prime} \mathrm{N}, 121^{\circ}\right.$ $32^{\prime} \mathrm{E}$ ), the parameters of the tide, wind and water depth, and etc. , are as follows:

On that day, the time of tide: $6: 33$ with a height of $51 \mathrm{~cm}$; $11: 57,323 \mathrm{~cm} ; 18: 33,46 \mathrm{~cm}$. The tidal datum plane is $163 \mathrm{~cm}$ beneath the average sea level, in the time zone: GMT+8; with a southerly wind above the sea, and a wind speed of about $4 \mathrm{~m} / \mathrm{s}$; and with a water depth of about 10 meters in the tested sea area waters.The statistical significant wave heights $\left(\mathrm{H}_{1 / 3}\right)$ are respectively $0.279 \mathrm{~m}, 0.264 \mathrm{~m}$, and $0.251 \mathrm{~m}$.

Figure 8 indicates the wave spectra of the coastal flow phase at Xiaoheishi sea area in Dalian City. On the very day when the test is carried out at Xiaoheishi sea area $\left(38^{\circ} 51^{\prime} \mathrm{N}, 121^{\circ}\right.$ $15^{\prime} \mathrm{E}$ ), the parameters of the tide, wind and water depth, and etc., are as follows:

On that day, the time of tide: $2: 12$ with a height of $100 \mathrm{~cm}$; $13: 48,231 \mathrm{~cm} ; 19: 36,121 \mathrm{~cm}$. The tidal datum plane is $145 \mathrm{~cm}$ beneath the average sea level, in the time zone: GMT+8; with a southerly wind above the sea, and a wind speed of about $4 \mathrm{~m} / \mathrm{s}$; and with a water depth of about 10 meters in the tested sea area waters. The statistical significant wave heights $\left(\mathrm{H}_{1 / 3}\right)$ are respectively $0.31 \mathrm{~m}, 0.24 \mathrm{~m}$.

Figure 9 indicates the wave spectra of the coastal flow phase at Jinghaiwei sea area in Rongcheng City. On the very day when the test is carried out at Jinghaiwei sea area $\left(37^{\circ} 10^{\prime} \mathrm{N}\right.$, $122^{\circ} 25^{\prime} \mathrm{E}$ ), the parameters of the tide, wind and water depth, and etc. , are as follows:

On that day, the time of tide: $6: 56$ with a height of $61 \mathrm{~cm}$; $12: 46,236 \mathrm{~cm} ; 19: 02,66 \mathrm{~cm}$. The tidal datum plane is $151 \mathrm{~cm}$ beneath the average sea level, in the time zone: GMT+8; with a noutherly wind above the sea, and a wind speed of about $5 \mathrm{~m} / \mathrm{s}$; and with a water depth of about 15 meters in the tested sea area waters. The statistical significant wave heights $\left(\mathrm{H}_{1 / 3}\right)$ are respectively $0.56 \mathrm{~m}, 0.49 \mathrm{~m}$.

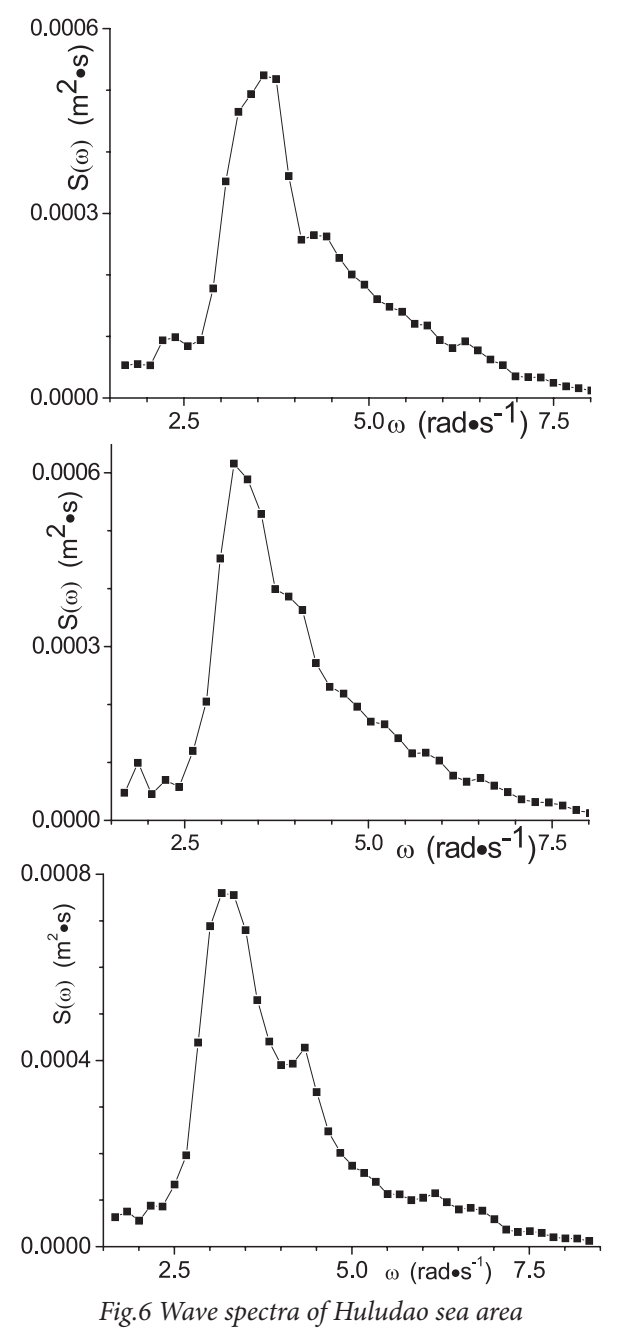



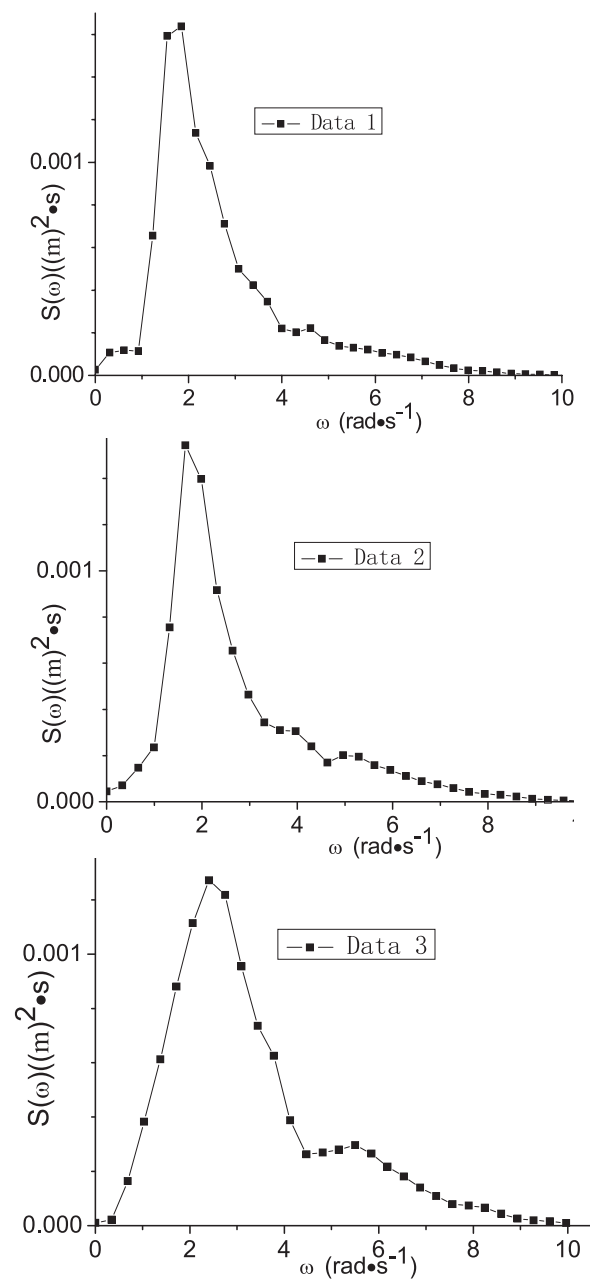

Fig.7 Wave spectra of Xiaoping Island sea area
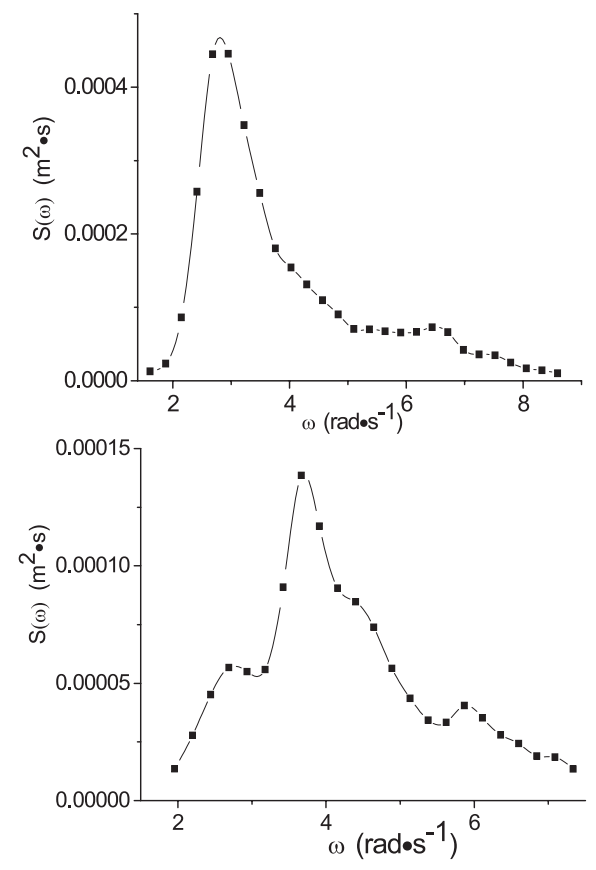

Fig.8 Wave spectra of Xiaoheishi sea area
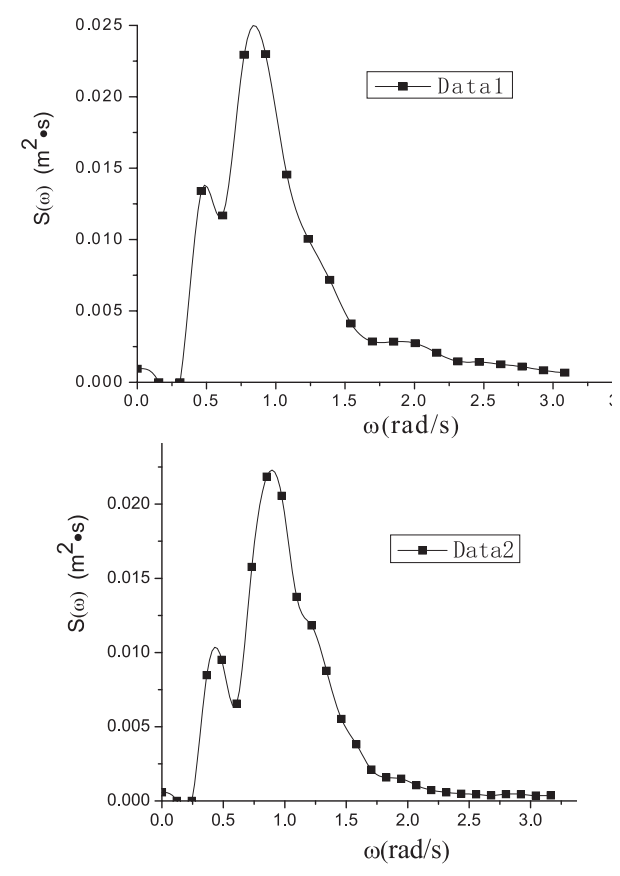

Fig.9 Wave spectra of Jinghaiwei sea area

Figure 10 shows the nondimensional spectrum findings of measured ocean wave and some theoriotical ocean wave spectrums.

(a)

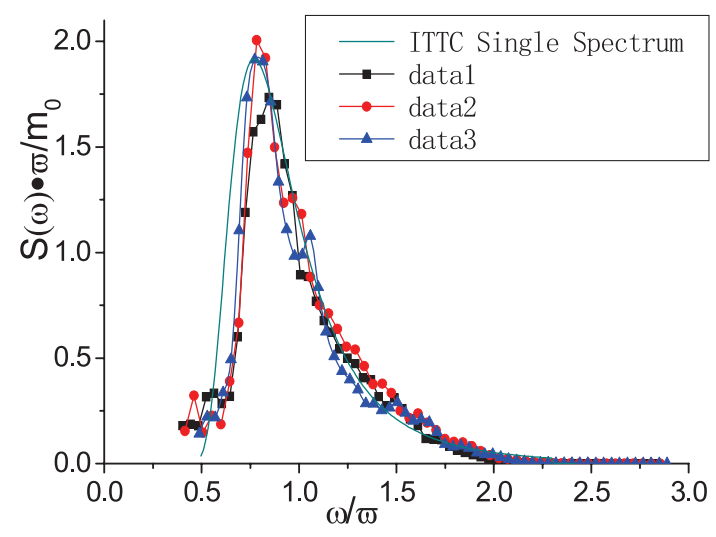

(b)

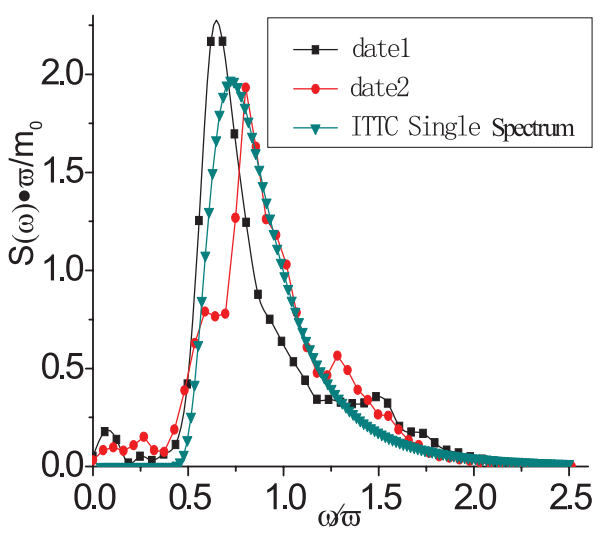


(c)

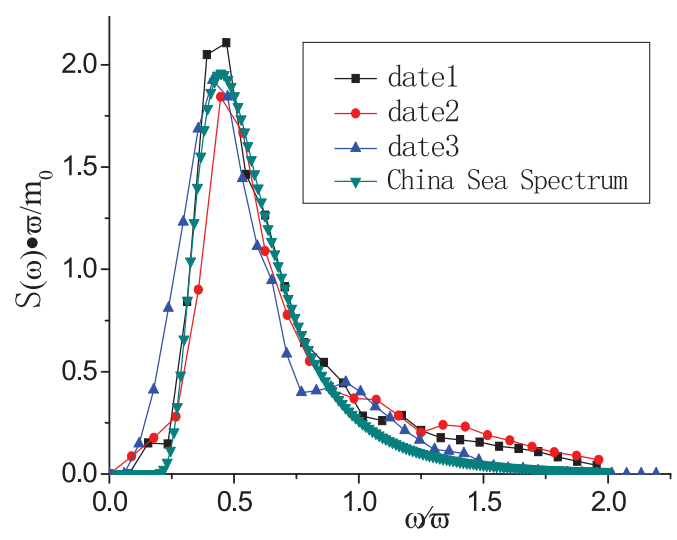

(d)

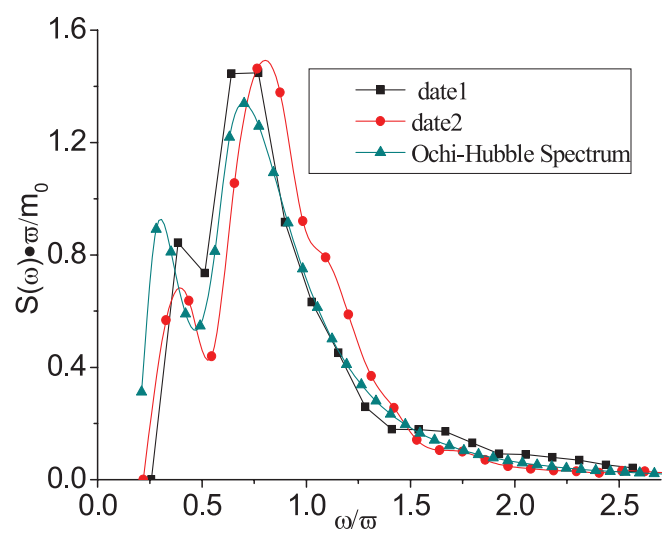

Fig.10 Nondimensional wave spectra of Huludao(a) Xiaoheishi(b) Xiaoping Island (c) and Jinghaiwei (d) sea area

From Figure 10, we know that:

1. According to the central frequency, frequency range, energy distribution, the situation of single-peak and multi-peak of the measurement spectrum, an appropriate ocean wave spectrum that is similar to the measurement spectrum can be found, which illustrates that the coastal ocean wave spectrums of the Yellow Sea and the Bohai Sea are similar to the ocean wave spectrum;

2. The central frequencies of ocean wave spectrum in different sea areas of the Yellow Sea and the Bohai Sea differ greatly and are similar to different ocean spectrums, which are mainly similar to ITTC single parameter spectrum and China sea spectrums, while some Double-peaked spectrums caused by multi wind fields are generally similar to Ochi-Hubble spectrums.

\section{CONCLUSION}

Buoy wave height meter which is made by adopting the gravity acceleration principle can effectively measure sea wave; the measurement and analysis of sea wave in coastal waters of the Yellow Sea and Bohai Sea show that conditions including weather and tide have significant effect on coastal wave parameters. Under suitable environmental conditions, features of wave spectra in covered coastal waters are similar to those of ocean wave spectra.

\section{ACKNOWLEDGEMENT}

The author thanks the anonymous reviewers for their valuable remarks and comments. This work is supported by National Natural Science Fund of China (Grant No. 51209054).

\section{REFERENCES}

3. Zuo Qihua. Development and Application of Wave Measurement Technology. Research report, Nanjing Hydraulic Research Institute, 2008.

4. Sun Shuzheng, Li Jide, Zhao Xiaodong. Research on large scale model test in real ocean wave environment. Journal of Harbin Engineering University.2009.5

5. Tang Yuanguang, Wang Jinping. SZF Buoy Wave Height Meter System. Research report, Ocean University of China,2008.

6. Li Jide. Seakeeping Performance of Ships. Harbin Engineering University. Publications, China 2003

7. Yu Yuxiu, Liu Shuxue. Random Wave and Engineering Application. Dalian University of Technology Press, 2011:137-186.

8. Ren Xuhe, Xie Botao, Song Zhuanling. Statistical Characteristics of the Double-peaked Wave Spectra in the Deep Area of the South China Sea. Advances in Marin Science. Vol.32 No.2,2014.4:148-154

9. Yoshiaki Hirakawa, Takehiko Takayama, Tsugukiyo Hirayama. Development of Ultra-Small-Buoy for measurement directional waves. ICMT2012, 25-28 June 2012, Harbin

10. Yoshiaki Hirakawa,Takehiko Takayama,Tsugukiyo Hirayama. Development of Ultra-Small-Buoy for measurement directional waves[J].Yokohama National University, Yokohama-City, Japan,2012.

11. Shuzheng Sun, Huilong Ren, Xiaodong Zhao, Jide Li. EXPERIMENTAL STUDY OF TWO LARGE-SCALE MODELS' SEAKEEPING PERFORMANCE IN COASTAL WAVES. Brodogradnja. 2015.6 
CONTACT WITH THE AUTHOR

Hui LI

e-mail: huili@hrbeu.edu.cn

College of Shipbuilding Engineering

Harbin Engineering University

Nantong Street, No.145

Harbin City, 150001

Heilongjiang province

CHINA 